\title{
SOME TENTATIVE GONGLUSIONS ON THE BOLTZ TEST IN GENERAL PARALYSIS OF THE INSANE.
}

\author{
By J. ERNEST NICOLE, Warrington.*
}

\section{INTRODUGTION.}

Results from the Boltz test have been published from time to time during the past three years, but so far the different investigators have seemed singularly at variance concerning their conclusions, although between them the total number of cases of general paralysis reported upon amounts to some 220 .

Earlier observations from this hospital were published by Dr. J. P. Steel and myself ${ }^{5}$ in 1926, but now that the test has been used here for just over two years the time seems to have come when something a little more definite might be said about it, especially as regards some points raised by other authors.

Most observers agree that the test is generally positive in general paralysis, some would even say invariably ${ }^{1,2,3,6,7,10}$. At the other extreme are some who think it is positive in most fluids even apart from cerebrospinal syphilis ${ }^{8,11}$. It has been suggested ${ }^{2}$ that the test follows the globulin reaction in its results, and that it alters in company with the others after malarial therapy.3. On the other hand one observer ${ }^{4}$ says it remains positive after malaria.

\section{NATURE OF GASES.}

The observations that follow are based on a series of 346 Boltz tests performed on 267 patients, of whom 108 were cases of general paralysis. Of these 108, 56 were investigated by the Boltz test before malaria only, 21 before and after malaria, and another 31 after malaria only. The technique of he test is simple and has already been often described by others.

For comparison the general results of the globulin test were obtained from a rather larger series, viz., 672 tests on 496 cases, of which 180 were general paralytics, 126 tests being performed after therapeutic malaria. (See Table I.)

\footnotetext{
* From the County Mental Hospital, Winwick.
} 
TABLE I.

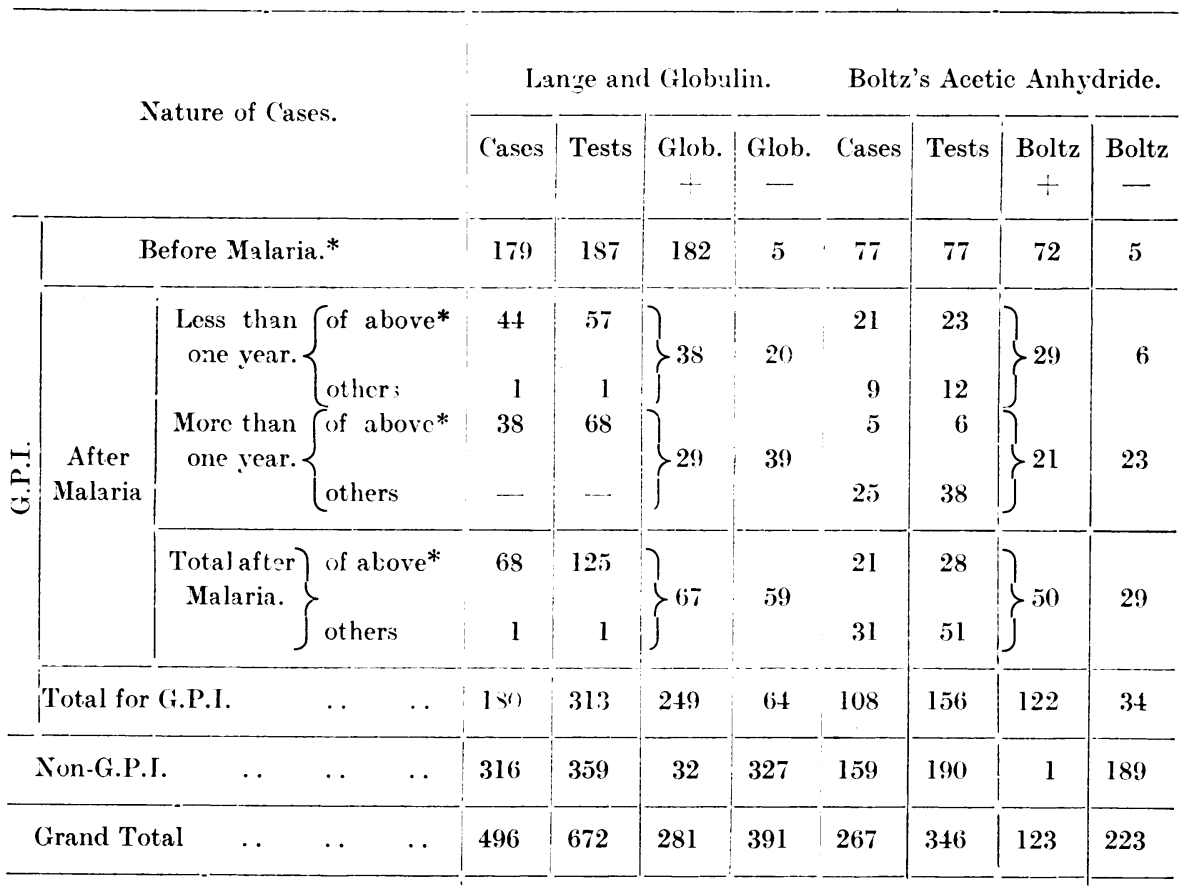

\section{RESULTS.}

On examining the tabulated resuits, two facts at once become obvious. Firstly, the Boltz test does not always agree with the globulin test; this is evident from the illustrative cases that have been chosen as fairly typical of the series (Table II). Secondly, it is not positive in the majority of fluids. In only 0.5 per cent. of non-G.P.I. fluids was it positive (one case), whereas the corresponding figure for the globulin series was 9 per cent.

In untreated paralytics the test was found negative in $6 \cdot 5$ per cent. of cases, but the globulin was so in only $2 \cdot 75$ per cent. This might perhaps be due to the Boltz test's only appearing positive later in the development of the disease than the globulin, especially since in several of these cases it was proved that the test became positive later even though malaria had been induced in the meantime. (This might be correlated with the behaviour of the test in fluids that first improved and then relapsed, as described below.) See Cases 133. 165 .

Reference to Table $I$ will show that the test certainly does become negative after malaria (See Cases 20, 53), but sometimes remains positive throughout several examinations (Case 100). But whereas the number of globulin tests thus becoming negative is $47 \cdot 8$ per cent., only $36 \cdot 7$ per cent. of the Boltz follow suit. 
It is interesting to compare the relative rate of change of these two tests, by contrasting the results obtained within one year of malaria with those to be found more than a year after. Within one year, 34.5 per cent. of the globulins are negative as against 14.7 per cent. negative Boltz; after one year, however, the respective percentages are $57 \cdot 4$ and $52 \cdot 3$, showing that the Boltz test changes more slowly at first but tends to catch up the globulin results later. (See Cases 17, 57.)

TABLE II.

Illustrative Cases.

\begin{tabular}{|c|c|c|c|c|c|c|c|}
\hline & \multicolumn{3}{|c|}{ Before Malaria. } & \multicolumn{4}{|c|}{ After Malaria. } \\
\hline $\begin{array}{c}\text { ('ase } \\
\text { Number }\end{array}$ & Lange. & Globulin. & Boltz. & $\begin{array}{c}\text { Months } \\
\text { since } \\
\text { Malaria. }\end{array}$ & Lange. & Globulin. & Boltz. \\
\hline 133 & 34555,43300 & t & - & 2 & 23455,33200 & + & + \\
\hline 165 & 55555,43310 & + & 一 & $\begin{array}{l}2 \\
8\end{array}$ & $\begin{array}{l}14555,43000 \\
24544,31000\end{array}$ & + & $\begin{array}{l}+ \\
+\end{array}$ \\
\hline 20 & 55555,42222 & + & & $\begin{array}{l}19 \\
25 \\
42\end{array}$ & $\begin{array}{l}11555,43100 \\
00321,10000 \\
02344,43210\end{array}$ & $\begin{array}{l}+ \\
-\end{array}$ & - \\
\hline 53 & 55554,31000 & t & & $\begin{array}{r}3 \\
11 \\
17 \\
33\end{array}$ & $\begin{array}{l}00114,55400 \\
01123,32100 \\
01122,21000 \\
00011,10000\end{array}$ & $\begin{array}{l}+ \\
- \\
-\end{array}$ & - \\
\hline 100 & 55555,54310 & + & + & $\begin{array}{r}1 \\
6 \\
16\end{array}$ & $\begin{array}{l}55555,55543 \\
55555,55443 \\
55555,55432\end{array}$ & $\frac{+}{-t}$ & $\begin{array}{l}+ \\
+ \\
+\end{array}$ \\
\hline 17 & 55555,54322 & + & & $\begin{array}{l}20 \\
26 \\
40\end{array}$ & $\begin{array}{l}3455 \tilde{5}, 43100 \\
13345,52100 \\
12332,11000\end{array}$ & - & + \\
\hline 57 & 55555,51100 & + & & $\begin{array}{l}14 \\
20 \\
30\end{array}$ & $\begin{array}{l}00233,21100 \\
00033,20000 \\
00011,10000\end{array}$ & - & + \\
\hline 132 & 55555,55431 & + & + & $\begin{array}{l}10 \\
21\end{array}$ & $\begin{array}{l}34555,44321 \\
03555,54320\end{array}$ & - & - \\
\hline 108 & 55555,54330 & + & & $\begin{array}{r}2 \\
6 \\
20\end{array}$ & $\begin{array}{l}35555,42200 \\
34455,43100 \\
55555,54321\end{array}$ & $\frac{+}{+}$ & $\begin{array}{l}+ \\
-\end{array}$ \\
\hline
\end{tabular}


It is, moreover, of interest to see how after both tests have been negative for some time the Boltz may remain negative even though the globulin again becomes positive. (Cases 132, 108.)

\section{CONGLUSIONS.}

Although nothing categorical can as yet be said about this test, the following tentative conclusions may be advanced.

1. The Boltz test is not usually positive in the cerebrospinal fluid except in presence - and almost exclusively in presence-of general paralysis.

2. The test does not always agree with the globulin test and may be positive when the latter is negative, and vice versa.

3. A positive Boltz test is almost invariably an indicator of general paralysis.

4. A negative Boltz test is not a reliable indicator of the absence of general paralysis, at least in the earlier stages.

5. The test tends to change after malarial treatment but not as freciuently as the globulin one.

6. When the test does alter, it does so less rapidly than the globulin test.

7. When a recession of an improved fluid occurs the Boltz test tends to remain negative for a longer period than the globulin reaction.

I am indebted to the Medical Superintendant, Dr. F. M. Rodgers, for permission to quote hospital material.

\section{REFERENGES.}

${ }^{1}$ Boltz, Amer. Jour. Psychiat., 1923, iii, 111.

${ }^{2}$ Grossman, Jour. of Ment. Sci., 1925, lxxi, 439.

3 Silverston, Board of Control Rep., 1925, 1:5.

${ }^{4}$ Harris, Brit. Med. Jour., 1926, i, 136.

5 Steel and Nicole, Brit. Jour. Ven. Dis., 1926, ii, 243.

${ }^{6}$ Flemming, Jour. of Ment. Sci., 1926, lxxii, 376.

7 Flemming, Board of Control Rep., 1926, ii, 39.

${ }^{8}$ TURn Bull, Board of Control Rep., 1926, ii, 35.

9 RoDgers, Board of Control Rep., 1926, ii, 22.

${ }^{10}$ Greenfield and Carmichael, Jour. Neurol. and Psy:hoprth., 1927, vii, 220.

11 Dencan, Jour. of Ment. Sci., 1927, lxxiii, 419. 